\title{
Balancing of residual stress in thin film iridium by utilizing chromium as an underlayer
}

Massahi, S.; Vu, L. M.; Ferreira, D. D.M.; Christensen, F. E.; Gellert, N.; Henriksen, P. L.; Svendsen, S.; Jegers, A. S.; Collon, M.; Landgraf, B.

Total number of authors:

15

Published in:

Space Telescopes and Instrumentation 2020: Ultraviolet to Gamma Ray

Link to article, DOI:

$10.1117 / 12.2576298$

Publication date:

2020

Document Version

Publisher's PDF, also known as Version of record

Link back to DTU Orbit

Citation (APA):

Massahi, S., Vu, L. M., Ferreira, D. D. M., Christensen, F. E., Gellert, N., Henriksen, P. L., Svendsen, S., Jegers, A. S., Collon, M., Landgraf, B., Girou, D.,' Thete, A., Shortt, B., Ferreira, I., \& Bavdaz, M. (2020). Balancing of residual stress in thin film iridium by utilizing chromium as an underlayer. In J-W. A. den Herder, S. Nikzad, \& K. Nakazawa (Eds.), Space Telescopes and Instrumentation 2020: Ultraviolet to Gamma Ray (Vol. 11444).

[114444N] SPIE - International Society for Optical Engineering. Proceedings of SPIE - The International Society for Optical Engineering Vol. 11444 https://doi.org/10.1117/12.2576298

\section{General rights}

Copyright and moral rights for the publications made accessible in the public portal are retained by the authors and/or other copyright owners and it is a condition of accessing publications that users recognise and abide by the legal requirements associated with these rights.

- Users may download and print one copy of any publication from the public portal for the purpose of private study or research.

- You may not further distribute the material or use it for any profit-making activity or commercial gain

- You may freely distribute the URL identifying the publication in the public portal 


\section{Balancing of residual stress in thin film iridium by utilizing chromium as an underlayer}

Massahi, S., Vu, L., Ferreira, D. D., Christensen, F., Gellert, N., et al.

S. Massahi, L. M. Vu, D. D. M. Ferreira, F. E. Christensen, N. Gellert, P. L. Henriksen, S. Svendsen, A. 'S Jegers, M. Collon, B. Landgraf, D. Girou, A. Thete, B. Shortt, I. Ferreira, M. Bavdaz, "Balancing of residual stress in thin film iridium by utilizing chromium as an underlayer," Proc. SPIE 11444, Space Telescopes and Instrumentation 2020: Ultraviolet to Gamma Ray, 114444N (13 December 2020); doi: 10.1117/12.2576298 


\title{
Balancing of residual stress in thin film iridium by utilizing chromium as an underlayer
}

\author{
S. Massahi ${ }^{1}$, L. M. Vu ${ }^{1}$, D. D. M. Ferreira ${ }^{1}$, F. E. Christensen ${ }^{1}$, N. Gellert ${ }^{1}$, P. L. Henriksen ${ }^{1}$, \\ S. Svendsen ${ }^{1}$, A. 'S Jegers ${ }^{1}$, M. Collon ${ }^{2}$, B. Landgraf ${ }^{2}$, D. Girou ${ }^{2}$, A. Thete ${ }^{2}$, B. Shortt ${ }^{3}$, I. \\ Ferreira $^{3}$, M. Bavdaz ${ }^{3}$, \\ ${ }^{1}$ DTU Space, Technical University of Denmark, Elektrovej building 327/328,2800 Kgs. Lyngby, Denmark \\ ${ }^{2}$ cosine, Oosteinde 36, 2361 HE Warmond, The Netherlands \\ ${ }^{3}$ ESTEC, European Space Research and Technology Centre, Keplerlaan 1, 2201 AZ Noordwijk, The Netherlands
}

Keywords: X-ray optics, DC magnetron sputtering, residual thin film stress, X-ray reflectometry, Atomic force microscopy, stylus profilometry, Athena mission, Silicon Pore Optics

\begin{abstract}
As part of the thin film development for the Athena X-ray telescope and X-ray optics in general, we investigated the residual stress in iridium and chromium thin films deposited using direct current magnetron sputtering. Residual stresses in thin films can affect the performance and adhesion properties of the fabricated thin film coated X-ray optics. We characterized the thin films using X-ray reflectometry to determine the thin film thicknesses and stylus profilometry to determine the residual film stresses. To counterbalance the compressive stress identified in the iridium thin films, we introduced a chromium thin film layer for which the residual stress is tensile beneath the iridium film. However, chromium thin films are known to exhibit a grainy growth resulting in a high surface roughness which was also observed in this work. In this paper, we evaluated the effect on the iridium surface roughness when introducing a chromium underlayer and discussed the effect on the X-ray optics performance.
\end{abstract}

\section{INTRODUCTION}

The demand for X-ray optics increases and so do their performance requirements. Iridium (Ir) thin film coatings have proven to be very robust and exhibit excellent reflective properties within the X-ray regime. However, the residual stress in Ir thin films is high and studies show that thin film Ir coatings with a thickness of 10-30 nm exhibit residual compressive stress ${ }^{1}$ as illustrated in Figure 1.

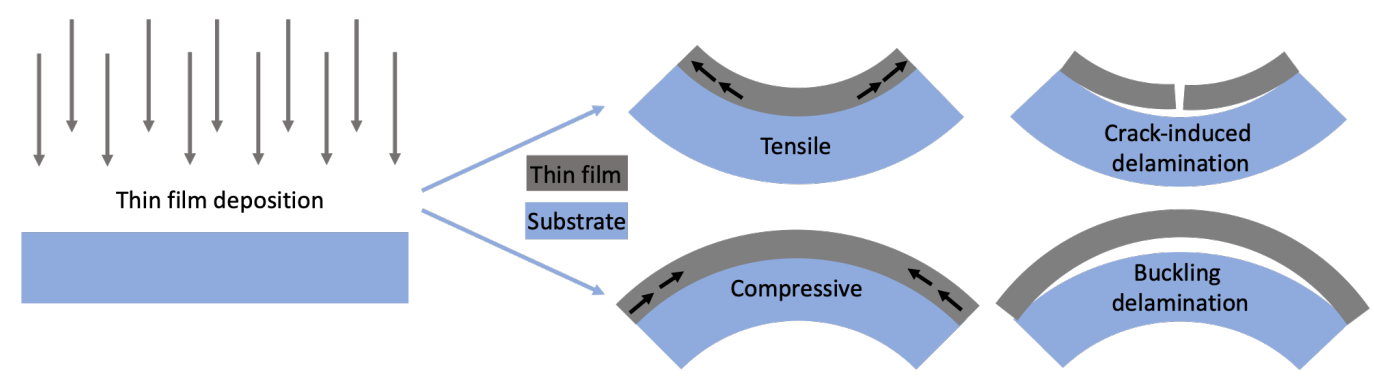

Figure 1: Illustration of the substrate bending when depositing a tensile or compressive thin film.

Further author information:

Sonny Massahi: E-mail: sonmas@space.dtu.dk

Space Telescopes and Instrumentation 2020: Ultraviolet to Gamma Ray, edited by Jan-Willem A. den Herder Shouleh Nikzad, Kazuhiro Nakazawa, Proc. of SPIE Vol. 11444, 114444N · (c) 2020 SPIE CCC code: $0277-786 X / 20 / \$ 21 \cdot$ doi: $10.1117 / 12.2576298$

Proc. of SPIE Vol. $11444114444 \mathrm{~N}-1$ 
Large residual film stress can lead to mirror deformations both local and global deformations which reduces the performance of the X-ray optics ${ }^{2}$. It can also lead to delamination or cracking ${ }^{3}$ of the film.

A high residual compressive stress can be counterbalanced by applying a thin film with residual tensile stress properties in a bilayer configuration with the Ir film. Chromium $(\mathrm{Cr})$ exhibits such properties and was utilized for the operating space-borne Chandra X-ray observatory. The X-ray reflecting mirrors for the Chandra mission utilized $\sim 10 \mathrm{~nm}$ Ir on top of $\sim 30 \mathrm{~nm} \mathrm{Cr}^{4}$. The Advanced telescope for high-energy astrophysics (Athena) the ESA selected L-class mission ${ }^{5}$ plans to use Ir thin film coatings with the Silicon Pore Optics (SPO) technology ${ }^{6}$. Ir and $\mathrm{Cr}$ thin film coatings have been under development for Athena and other X-ray telescopes at DTU Space during the last 15 years $^{7-14}$. As part of the industrialization of the thin film coatings for Athena a dedicated coating chamber was designed, installed and commissioned at cosine and the thin film coatings discussed in this work have been produced herein. We investigated the required $\mathrm{Cr}$ thickness to counterbalance the residual stress exhibited by single layer Ir films and the necessity of using Cr to avoid cracking and delamination of Ir.

\section{EXPERIMENTAL}

\subsection{Sample preparation}

Double-side polished diced silicon substrates, also referred to as witness samples, with dimensions $70 \mathrm{~mm} \times 10$ $\mathrm{mm} \times 0.775 \mathrm{~mm}(\mathrm{~L} \times \mathrm{W} \times \mathrm{H})$ were used to deposit the thin films onto. These substrates are not exposed to any processing steps other than dicing and plasma cleaning prior to thin film deposition compared to the SPO plates which undergo multiple process steps including photoresist pattering ${ }^{15}$. Prior to thin film deposition, the substrates were plasma cleaned using a Tepla plasma asher utilizing oxygen and nitrogen ions. The plasma cleaning ensures a clean silicon surface only exposed to the hydrocarbons in the atmosphere when transferred from the plasma cleaning chamber to the magnetron sputtering chamber ${ }^{15}$. The surface roughness derived from X-ray Reflectometry (XRR) and Atomic Force Microscopy (AFM) after exposure to plasma cleaning is the order of $0.2-0.4 \mathrm{~nm}$. The thin film depositions were carried out in the Athena dedicated coating facility ${ }^{16}$ installed at cosine. A target conditioning was performed before exposing the substrates to the sputtered atoms by presputtering the materials for five minutes. We applied a power density of $2.9 \mathrm{~W} / \mathrm{cm}^{3}$ to the Ir target and 2.2 $\mathrm{W} / \mathrm{cm}^{3}$ to the $\mathrm{Cr}$ target in an argon atmosphere with a pressure of $3.5 \times 10^{-3}$ mbar.

The list of samples is presented in Table 1. Witness samples denoted with csxxxxx were used for AFM and XRR and samples denoted with sxxxx were used for stylus profilometry.

\subsection{Characterization tools}

\subsubsection{X-ray reflectometry}

XRR data at $8.048 \mathrm{keV}$ were obtained with the Rigaku SmartLab at DTU Nanolab which has a Cu K $\alpha$ X-ray source and a $\mathrm{D} /$ teX Ultra 250 silicon strip detector. The $\theta-2 \theta$ scans were performed in the incidence angle range $0-4^{\circ}$ with a step size of $0.02^{\circ}$ and 4 seconds exposure time per data point. Once the $\theta-2 \theta$ scan was completed, the direct beam was used to normalize the intensity measured in the angle scan.

To characterize the same set of samples at a lower energy, $\theta-2 \theta$ scans were performed with the Low-Energy X-ray Reflectometer (LEXR) at DTU Space ${ }^{17,18}$. The reflectometer has a $1.487 \mathrm{keV} \mathrm{Al} \mathrm{source,} \mathrm{and} \mathrm{the} \mathrm{detector}$ is a $2 \mathrm{D}$ CCD camera. Each sample was scanned from $0^{\circ}$ to $17.5^{\circ}$ in incidence angle with a step size of $0.05^{\circ}$. The beam was shaped by a slit size of $1.0 \mathrm{~mm} \times 0.5 \mathrm{~mm}$ and the slit size at the detector opening was $3.0 \mathrm{~mm}$ $\times 4.0 \mathrm{~mm}$. 
Table 1: Thin film coated samples.

\begin{tabular}{lcc:ccc}
\hline Sample ID & Material & Aimed thickness $(\mathrm{nm})$ & Sample ID & Material & Aimed thickness (nm) \\
\hline $\operatorname{cs} 00100$ & $\mathrm{Ir}$ & 10 & $\operatorname{cs} 00166, \mathrm{~s} 1238$ & $\mathrm{Cr} / \mathrm{Ir}$ & $10 / 10$ \\
$\operatorname{cs} 00106$ & $\mathrm{Ir}$ & 30 & $\operatorname{cs} 00168, \mathrm{~s} 1239$ & $\mathrm{Cr} / \mathrm{Ir}$ & $15 / 10$ \\
$\operatorname{cs} 00112$ & $\mathrm{Ir}$ & 50 & $\operatorname{cs} 00170, \mathrm{~s} 1240$ & $\mathrm{Cr} / \mathrm{Ir}$ & $20 / 10$ \\
$\operatorname{cs} 00118$ & $\mathrm{Ir}$ & 50 & $\operatorname{cs} 00172, \mathrm{~s} 1241$ & $\mathrm{Cr} / \mathrm{Ir}$ & $25 / 10$ \\
$\operatorname{cs} 00156$ & $\mathrm{Cr}$ & 5 & $\operatorname{cs} 00174, \mathrm{~s} 1242$ & $\mathrm{Cr} / \mathrm{Ir}$ & $10 / 30$ \\
$\operatorname{cs} 00158, \mathrm{~s} 1222$ & $\mathrm{Cr}$ & 10 & $\operatorname{cs} 00176$ & $\mathrm{Cr} / \mathrm{Ir}$ & $15 / 30$ \\
$\operatorname{cs} 00160$ & $\mathrm{Cr}$ & 15 & $\operatorname{cs} 00178, \mathrm{~s} 1243$ & $\mathrm{Cr} / \mathrm{Ir}$ & $20 / 30$ \\
$\operatorname{cs} 00162$ & $\mathrm{Cr}$ & 20 & $\operatorname{cs} 00180$ & $\mathrm{Cr} / \mathrm{Ir}$ & $25 / 30$ \\
$\operatorname{cs} 00165, \mathrm{~s} 1223$ & $\mathrm{Cr}$ & 30 & & & \\
\hline
\end{tabular}

\subsubsection{Stylus profilometry}

A Dektak stylus profiler was utilized to measure the curvature of the silicon substrates before and after thin film deposition with the purpose of deriving the residual film stress. We performed three measurements before and after coating and used the average value for calculation of the thin film stress. The samples were placed on a flat engraved platform in order to align the sample properly and scanned across the length of the sample.. The total scan length is $55000 \mu \mathrm{m}$ with a step size of $5 \mu \mathrm{m}$ with a height resolution of $1 \mathrm{~nm}$.

\subsubsection{Atomic force microscopy}

AFM was performed on two samples (cs00166 and cs00168) using the Bruker Dimension Icon AFM at DTU Nanolab. Each sample was scanned in three separate positions as illustrated in Figure 2, with a scan area of $1 \times 1$ $\mu^{2}$. The first scan area is in the center of the sample and the distances to the second and third positions are $11.7 \mathrm{~mm}$ and $23.3 \mathrm{~mm}$, respectively. The AFM scans were captured with a scan rate of $0.5 \mathrm{~Hz}$ and a resolution of $512 \times 512$ pixels using a ScanAsyst mode that automatically optimizes the scanning parameters of the PeakForce Tapping technique.

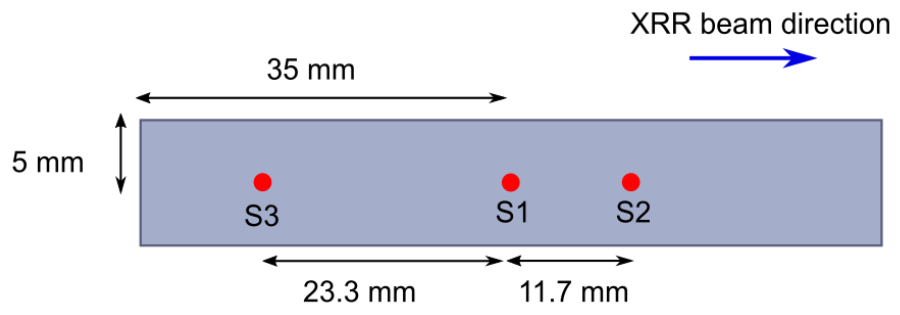

Figure 2: AFM was used to image the surface of $\mathrm{Cr} / \mathrm{Ir}$ coatings in three positions. The scan size is $1 \times 1 \mathrm{\mu m}^{2}$. 


\section{RESULTS AND DISCUSSION}

\section{$3.1 \mathrm{X}$-ray reflectometry}

The properties of the thin film coatings, such as thickness, roughness and material density, were determined by fitting the XRR data using the differential evolution algorithm available in the IMD software ${ }^{19}$. The XRR data obtained of $\mathrm{Cr}$ single layer coatings were fitted with a model structure composed of a $\mathrm{Si}$ substrate, a native $\mathrm{SiO}_{2}$ layer and a $\mathrm{Cr}$ layer. The $\mathrm{SiO}_{2}$ thickness was fixed to $2.0 \mathrm{~nm}$ (typical value for native grown oxide ${ }^{20}$ ) and the roughness was coupled to that of the $\mathrm{Si}$ substrate. For data acquired at $1.487 \mathrm{keV}$, we introduce an overlayer of hydrocarbons (C-H-O) to the model structure with a density fixed to $1.0 \mathrm{~g} / \mathrm{cm}^{3}{ }^{21}$. At $8.048 \mathrm{keV}$, the presence of the hydrocarbon layer is not detectable, and thus a simpler model is used to describe the data at this energy.

The best-fit parameters are shown in Table 2 and the XRR data of the single layer $\mathrm{Cr}$ films are presented in Figure 3 with the best-fit model. The largest residuals are observed in the valleys of the Kiessig fringes. The average modeled $\mathrm{Cr}$ densities were $7.0 \mathrm{~g} / \mathrm{cm}^{3}$ and $7.1 \mathrm{~g} / \mathrm{cm}^{3}$ derived from data acquired at $1.487 \mathrm{keV}$ and 8.048 $\mathrm{keV}$, respectively, corresponding to respectively $97 \%$ and $99 \%$ of the bulk density of $7.2 \mathrm{~g} / \mathrm{cm}^{3} 22$.

The surfaces of the Cr layers are approximately a factor three higher than the surface roughness of single layer iridium, and the roughness tended to increase with the layer thickness. The best-fit thickness of the C-H-O overlayer derived from the $1.487 \mathrm{keV}$ XRR data was in the range $1.3-1.5 \mathrm{~nm}$.

To model the XRR data obtained from the Cr/Ir bilayers, a layer of Ir is introduced to the model on top of $\mathrm{Cr}$ with the Ir density fixed to $22.4 \mathrm{~g} / \mathrm{cm}^{3}{ }^{16}$. Contrary to the fitting of the single layer films, we did not fit the $\mathrm{Cr}$ density in the bilayer model structure. The roughness of the $\mathrm{C}-\mathrm{H}-\mathrm{O}$ overlayer is coupled to the underlying Ir roughness. This decision was made after preliminary attempts to model the $\mathrm{Cr}$ density and the $\mathrm{C}-\mathrm{H}-\mathrm{O}$ roughness but with the added complexity to the model from the additional Ir layer, these parameters could not be constrained. We use a density of $7.2 \mathrm{~g} / \mathrm{cm}^{3}$ which is the value given in the optical constants in the IMD software ${ }^{19}$.

The best-fit parameters of the bilayer films are given in Table 3 and the models are presented with the measured XRR in Figures 4-5. Similarly to the results from the Cr single layers, the best-fit thickness of the C-H-O layer is within 1.3-1.6 nm. The Cr roughnesses derived from the $8.048 \mathrm{keV}$ XRR best-fit are higher than the Cr roughnesses derived from the $1.487 \mathrm{keV}$ best-fit. We attempted to fix the $\mathrm{Cr}$ roughness in the bilayer model to the value derived from the single layers, however the best-fit model was worse than the one shown in this manuscript.

The best-fit roughnesses of the $\mathrm{Cr}$ single layer and the bilayer films are plotted against the best-fit $\mathrm{Cr}$ layer thickness in Figure 6. There is a clear trend of increasing Cr roughness with increasing Cr thickness, but it is also worth noting that the $\mathrm{Cr}$ single layer films have higher roughnesses than the $\mathrm{Cr}$ layers with similar thicknesses in the bilayer configuration. This effect is not completely understood yet and is under investigation.

For the two sets of samples cs00166-cs00172 and cs00174-cs00180, the Ir layer thicknesses derived from 1.487 $\mathrm{keV}$ and $8.048 \mathrm{keV}$ data were close to the aimed $10 \mathrm{~nm}$ and $30 \mathrm{~nm}$. The Ir layer has consistently lower roughness compared to the Cr layer, regardless of the photon energy used to acquire the XRR data. We observe that the Ir surface roughness increases with increasing Cr thickness. Massahi et al. ${ }^{16}$ reported on an investigation of single layer films of Ir deposited on witness samples where it was found that $10 \mathrm{~nm}$ and $30 \mathrm{~nm}$ thick Ir films had roughnesses around $0.3-0.4 \mathrm{~nm}$. 
Table 2: Best-fit parameters of XRR data acquired for the single layer films of Cr.

\begin{tabular}{ccccccccc}
\hline \multirow{2}{*}{ Sample ID } & $\begin{array}{c}\text { Scan } \\
\text { date }\end{array}$ & $\begin{array}{c}\text { Scan } \\
\text { type }\end{array}$ & $\begin{array}{c}z_{\mathrm{Cr}} \\
(\mathrm{nm})\end{array}$ & $\begin{array}{c}z_{\mathrm{CHO}} \\
(\mathrm{nm})\end{array}$ & $\begin{array}{c}\sigma_{\mathrm{Cr}} \\
(\mathrm{nm})\end{array}$ & $\begin{array}{c}\sigma_{\mathrm{CHO}} \\
(\mathrm{nm})\end{array}$ & $\begin{array}{c}\sigma_{\text {subs }} \\
(\mathrm{nm})\end{array}$ & $\begin{array}{c}\rho_{\mathrm{Cr}} \\
\left(\mathrm{g} / \mathrm{cm}^{3}\right)\end{array}$ \\
\hline \multirow{2}{*}{$\operatorname{cs} 00156$} & $27-07-2020$ & $8.048 \mathrm{keV}$ & 5.2 & - & 0.79 & - & 0.29 & 7.11 \\
& $03-08-2020$ & $1.487 \mathrm{keV}$ & 5.0 & 1.3 & 0.71 & 0.27 & 0.28 & 7.06 \\
\hline \multirow{2}{*}{$\operatorname{cs} 00158$} & $27-07-2020$ & $8.048 \mathrm{keV}$ & 9.9 & - & 0.81 & - & 0.29 & 7.08 \\
& $03-08-2020$ & $1.487 \mathrm{keV}$ & 9.6 & 1.4 & 0.75 & 0.17 & 0.25 & 6.9 \\
\hline \multirow{2}{*}{$\operatorname{cs} 00160$} & $27-07-2020$ & $8.048 \mathrm{keV}$ & 14.7 & - & 0.89 & - & 0.32 & 7.06 \\
& $03-08-2020$ & $1.487 \mathrm{keV}$ & 14.3 & 1.4 & 0.84 & 0.33 & 0.32 & 7.04 \\
\hline \multirow{2}{*}{$\operatorname{cs} 00162$} & $27-07-2020$ & $8.048 \mathrm{keV}$ & 18.9 & - & 0.98 & - & 0.34 & 7.08 \\
& $03-08-2020$ & $1.487 \mathrm{keV}$ & 18.7 & 1.4 & 1.07 & 0.77 & 0.28 & 7.16 \\
\hline \multirow{2}{*}{$\operatorname{cs} 00165$} & $28-07-2020$ & $8.048 \mathrm{keV}$ & 29.4 & - & 1.11 & - & 0.40 & 7.01 \\
& $03-08-2020$ & $1.487 \mathrm{keV}$ & 28.8 & 1.5 & 1.24 & 0.97 & 0.35 & 6.98 \\
\hline
\end{tabular}
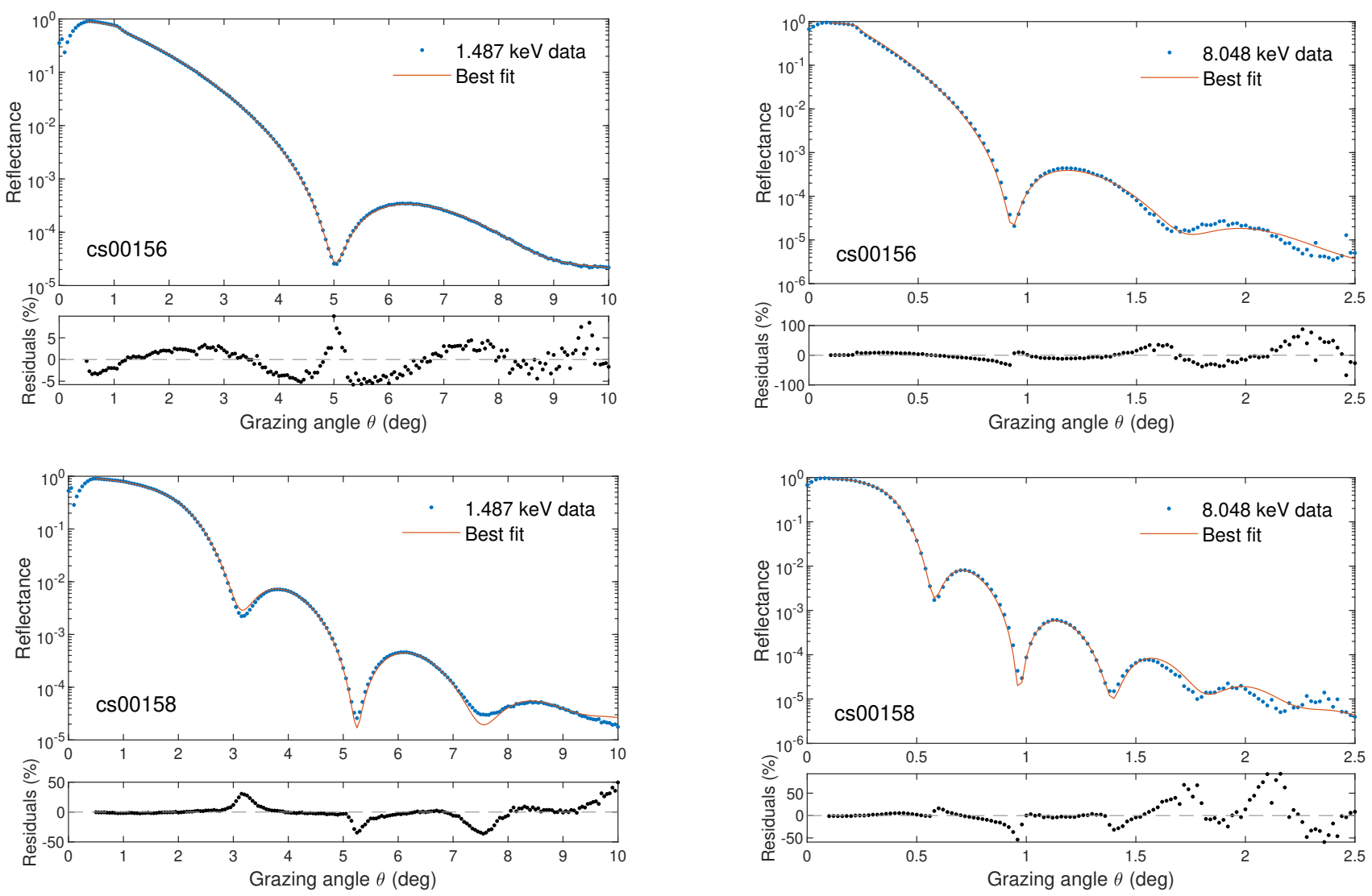

Figure 3: XRR at $1.487 \mathrm{keV}$ and $8.048 \mathrm{keV}$ of bilayer coated films with $\mathrm{Cr}$ and $10 \mathrm{~nm}$ Ir plotted with the best-fit model. 

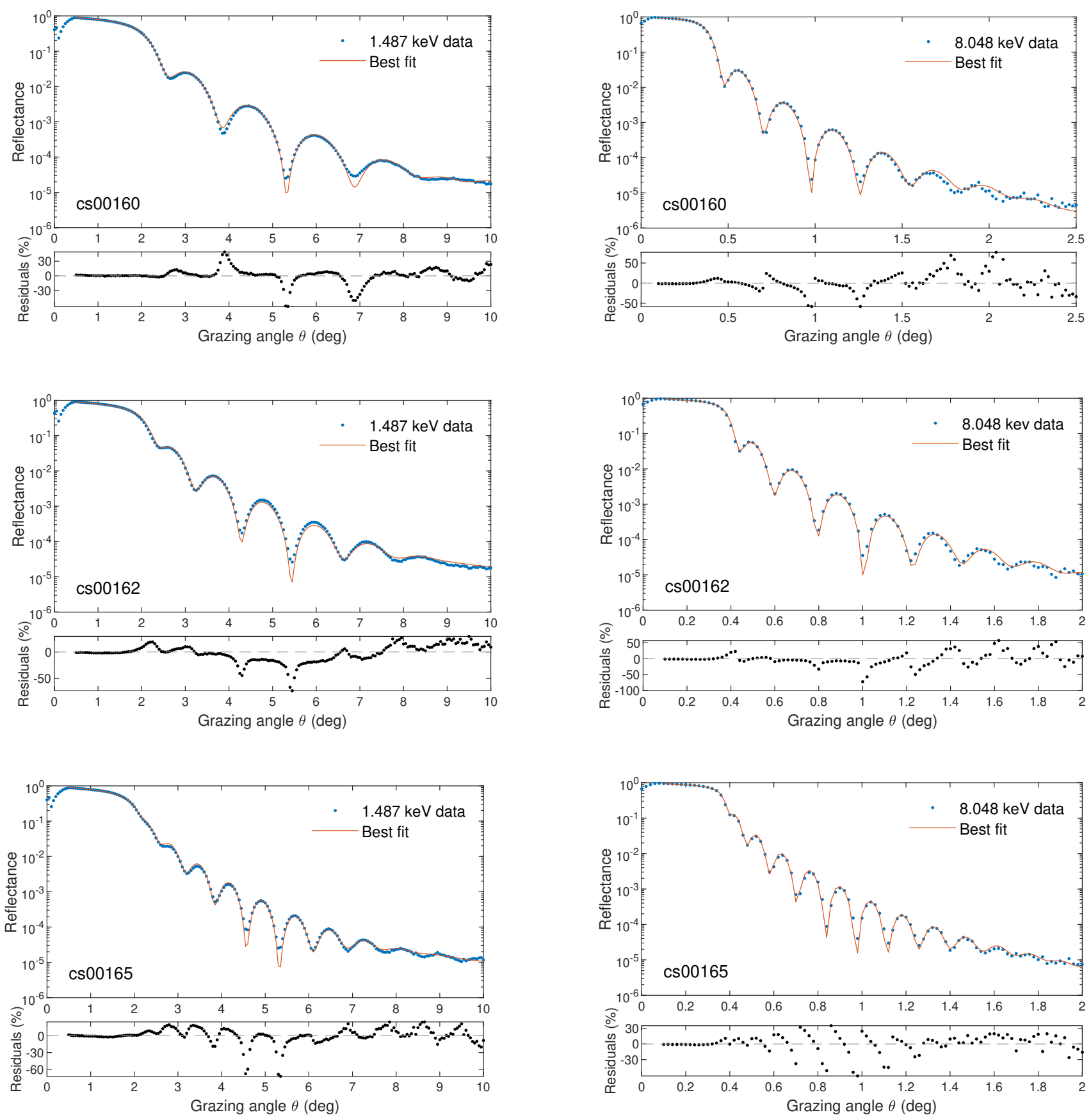

Figure 3 (cont.): XRR at $1.487 \mathrm{keV}$ and $8.048 \mathrm{keV}$ of bilayer coated films with $\mathrm{Cr}$ and $10 \mathrm{~nm}$ Ir plotted with the best-fit model. 
Table 3: Best-fit parameters of XRR data acquired for the bilayer coatings of $\mathrm{Cr}$ and Ir. The C-H-O surface roughness is coupled to the roughness of the Ir layer $\sigma_{\text {Ir }}$. Densities are fixed at $22.4 \mathrm{~g} / \mathrm{cm}^{3}$ for Ir and $7.2 \mathrm{~g} / \mathrm{cm}^{3}$ for Cr.

\begin{tabular}{|c|c|c|c|c|c|c|c|c|}
\hline Sample ID & $\begin{array}{l}\text { Scan } \\
\text { date }\end{array}$ & $\begin{array}{l}\text { Scan } \\
\text { type }\end{array}$ & $\begin{array}{c}z_{\mathrm{Cr}} \\
(\mathrm{nm})\end{array}$ & $\begin{array}{c}z_{\mathrm{Ir}} \\
(\mathrm{nm})\end{array}$ & $\begin{array}{c}z_{\mathrm{CHO}} \\
(\mathrm{nm})\end{array}$ & $\begin{array}{c}\sigma_{\mathrm{Cr}} \\
(\mathrm{nm})\end{array}$ & $\begin{array}{c}\sigma_{\mathrm{Ir}} \\
(\mathrm{nm})\end{array}$ & $\begin{array}{l}\sigma_{\text {subs }} \\
(\mathrm{nm})\end{array}$ \\
\hline \multirow{2}{*}{$\operatorname{cs} 00166$} & $13-10-2020$ & $1.487 \mathrm{keV}$ & 10.4 & 9.9 & 1.3 & 0.53 & 0.25 & 0.52 \\
\hline & $16-11-2020$ & $8.048 \mathrm{keV}$ & 10.3 & 10.0 & - & 0.59 & 0.32 & 0.52 \\
\hline \multirow{2}{*}{$\operatorname{cs} 00168$} & $13-10-2020$ & $1.487 \mathrm{keV}$ & 14.1 & 9.9 & 1.5 & 0.61 & 0.31 & 0.43 \\
\hline & $16-11-2020$ & $8.048 \mathrm{keV}$ & 14.0 & 9.9 & - & 0.67 & 0.35 & 0.41 \\
\hline \multirow{2}{*}{ cs00170 } & $13-10-2020$ & $1.487 \mathrm{keV}$ & 18.2 & 9.9 & 1.5 & 0.73 & 0.36 & 0.46 \\
\hline & $16-11-2020$ & $8.048 \mathrm{keV}$ & 18.1 & 9.9 & - & 0.77 & 0.39 & 0.40 \\
\hline \multirow{2}{*}{$\operatorname{cs} 00172$} & $13-10-2020$ & $1.487 \mathrm{keV}$ & 22.8 & 9.8 & 1.4 & 0.80 & 0.36 & 0.47 \\
\hline & $16-11-2020$ & $8.048 \mathrm{keV}$ & 22.7 & 9.9 & - & 0.86 & 0.43 & 0.45 \\
\hline \multirow{2}{*}{$\operatorname{cs} 00174$} & $13-10-2020$ & $1.487 \mathrm{keV}$ & 10.5 & 30.1 & 1.5 & 0.54 & 0.30 & 0.51 \\
\hline & $16-11-2020$ & $8.048 \mathrm{keV}$ & 10.5 & 30.0 & - & 0.60 & 0.35 & 0.53 \\
\hline \multirow{2}{*}{$\operatorname{cs} 00176$} & $13-10-2020$ & $1.487 \mathrm{keV}$ & 14.4 & 30.2 & 1.6 & 0.61 & 0.34 & 0.46 \\
\hline & $16-11-2020$ & $8.048 \mathrm{keV}$ & 14.4 & 30.1 & - & 0.68 & 0.38 & 0.42 \\
\hline \multirow{2}{*}{$\operatorname{cs} 00178$} & $23-10-2020$ & $1.487 \mathrm{keV}$ & 18.5 & 30.0 & 1.5 & 0.69 & 0.36 & 0.45 \\
\hline & $16-11-2020$ & $8.048 \mathrm{keV}$ & 18.5 & 29.9 & - & 0.76 & 0.41 & 0.45 \\
\hline \multirow{2}{*}{ cs00180 } & $16-10-2020$ & $1.487 \mathrm{keV}$ & 23.0 & 29.8 & 1.5 & 0.72 & 0.38 & 0.49 \\
\hline & $16-11-2020$ & $8.048 \mathrm{keV}$ & 23.0 & 29.9 & - & 0.80 & 0.42 & 0.48 \\
\hline
\end{tabular}
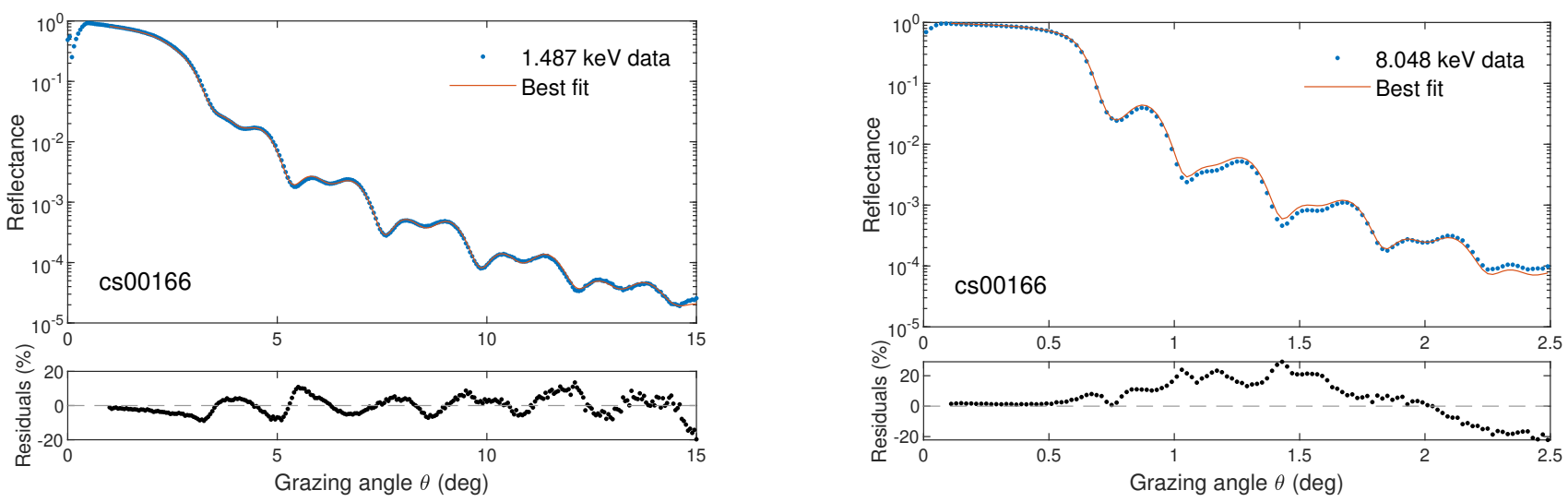

Figure 4: XRR at $1.487 \mathrm{keV}$ and $8.048 \mathrm{keV}$ of bilayer coated films with $\mathrm{Cr}$ and $10 \mathrm{~nm}$ Ir plotted with the best-fit model. 

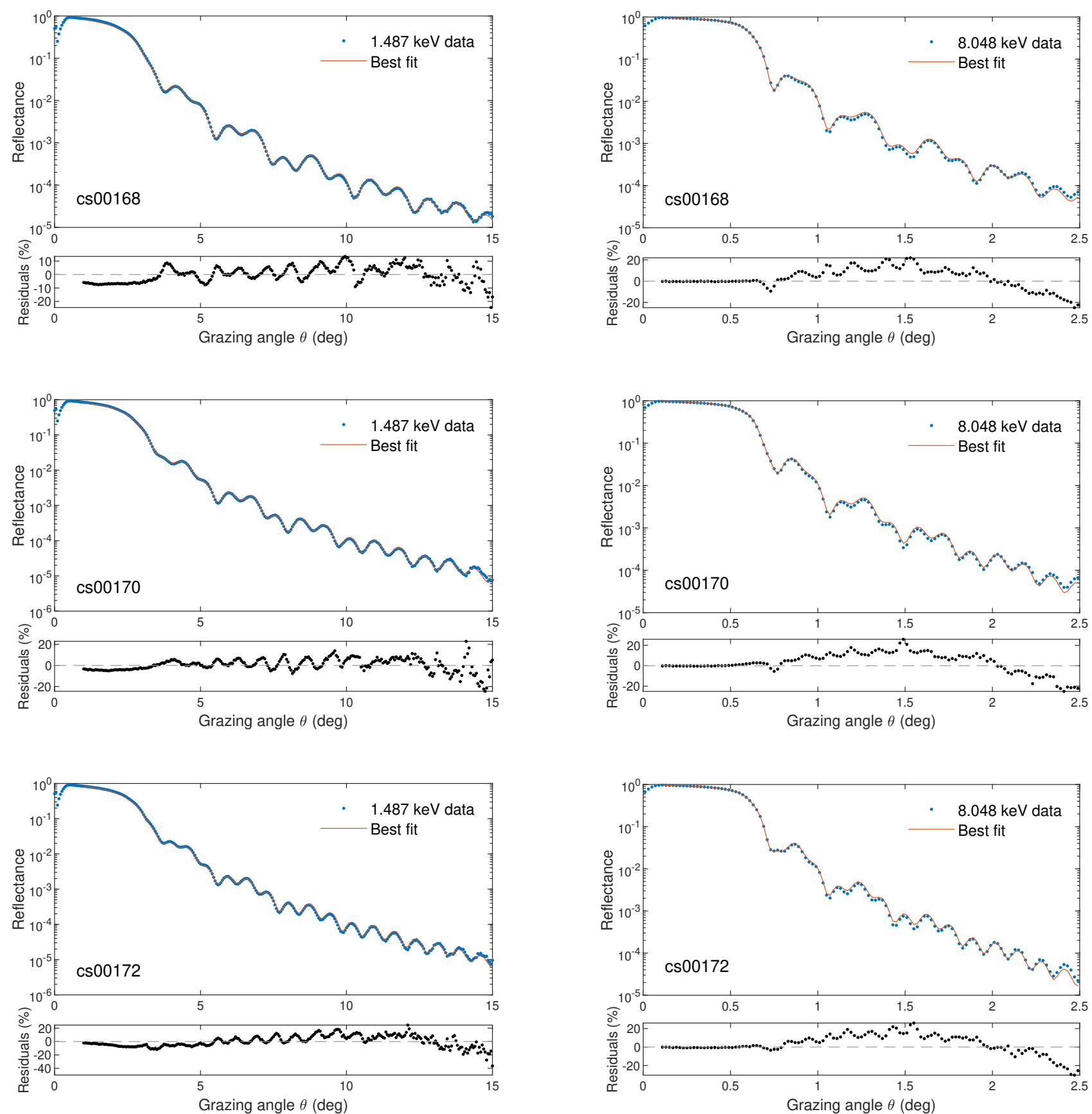

Figure 4 (cont.): XRR at $1.487 \mathrm{keV}$ and $8.048 \mathrm{keV}$ of bilayer coated films with $\mathrm{Cr}$ and $10 \mathrm{~nm}$ Ir plotted with the best-fit model. 

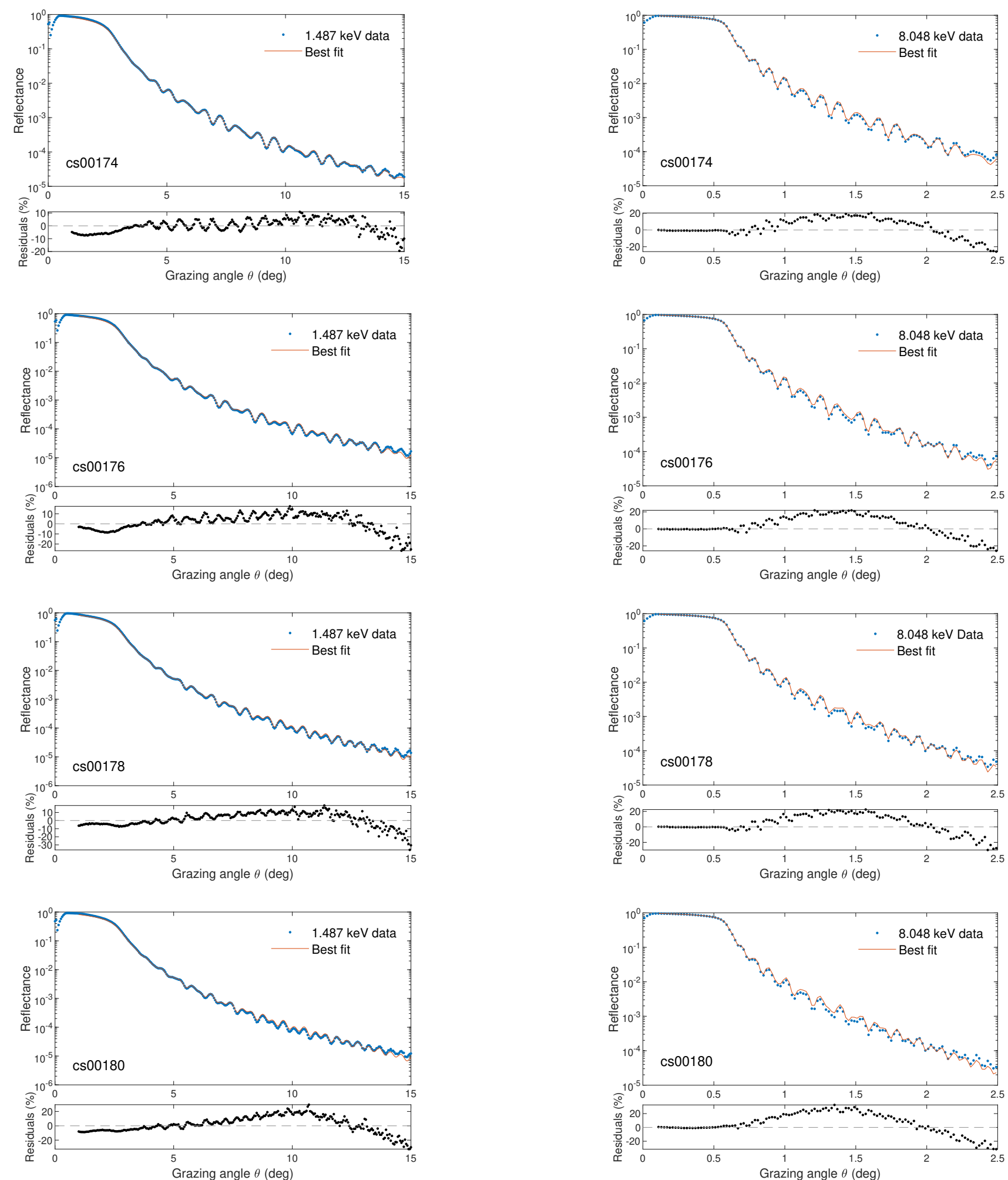

Figure 5: XRR at $1.487 \mathrm{keV}$ and $8.048 \mathrm{keV}$ of bilayer coated films with $\mathrm{Cr}$ and $30 \mathrm{~nm}$ Ir plotted with the best-fit model. 

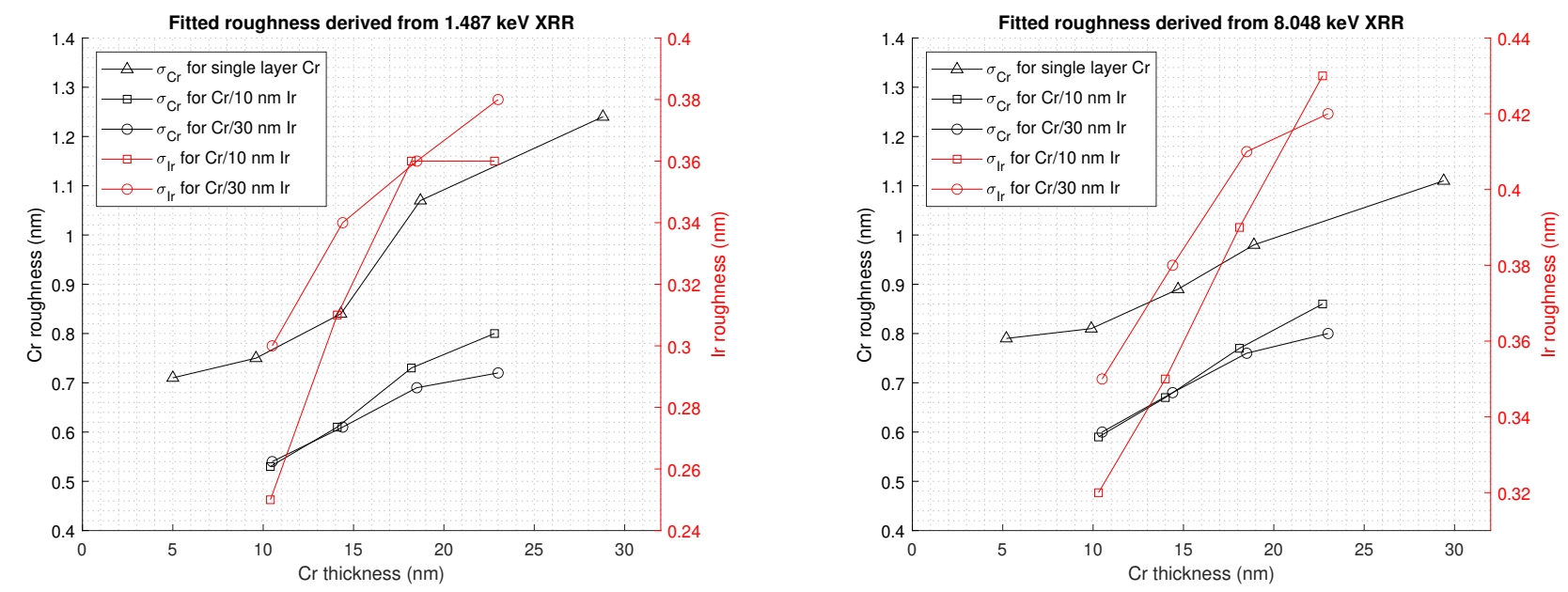

Figure 6: The best-fit roughness of $\mathrm{Cr}$ (black) and Ir (red) plotted against the best-fit Cr layer thickness derived from XRR at $1.487 \mathrm{keV}$ (left) and $8.048 \mathrm{keV}$ (right).

\subsection{Residual stress}

We calculated the residual stress of single layer Cr films and bilayer films composed of Cr and Ir using Stoney's equation $^{23}$. The key parameters in Stoney's equation are the curvature of the sample before and after thin film deposition as well as the film thickness, the substrate thickness and the substrate's Poisson's ratio and Young's modulus. Limitations of this technique, such as large substrate curvature prior to coating and sample positioning on the holder, can lead to large errors in the stress results. The samples used for these measurements are described in section 2.1.

The residual stress of the deposited films is shown in Figure 7. The single layer $\mathrm{Cr}$ films exhibit tensile stress on the order of $1674 \mathrm{MPa}$ and $3524 \mathrm{MPa}$ for the $\sim 10 \mathrm{~nm} \mathrm{Cr}$ and the $\sim 30 \mathrm{~nm} \mathrm{Cr}$ film, respectively. Similar results for single layer $\mathrm{Cr}$ deposited on aluminium substrates using DC magnetron sputtering were presented in Peng et al. ${ }^{24}$. Grachev et al. ${ }^{25}$ observed a residual stress level of approximately $2200 \mathrm{MPa}$ for a $20 \mathrm{~nm}$ thick Cr film deposited on silicon substrates with a native oxide layer (similar to substrates used in this work) using magnetron sputtering which is very similar to the result obtained in this study.

The residual tensile stress in the Cr films balances the residual compressive stress in Ir films. This is shown for $\sim 10 \mathrm{~nm}$ and $\sim 30 \mathrm{~nm}$ Ir films deposited on top of different Cr film thicknesses. The residual stress exhibited by the $10 \mathrm{~nm}$ Ir film is counterbalanced by a Cr film with a thickness of approximately $13 \mathrm{~nm}$.

The residual compressive stress of the $\sim 30 \mathrm{~nm}$ Ir film did not reach zero stress at $13 \mathrm{~nm}$ and based on the characteristics of the two data points and assuming a linear trend, zero stress could be achieved with a $25-30$ nm thick Cr film.

We performed a tape test on several single layer Ir film thicknesses ( $\sim 10 \mathrm{~nm}, \sim 30 \mathrm{~nm}, \sim 50 \mathrm{~nm}$ and $\sim 80 \mathrm{~nm})$ to determine the adhesion on witness samples. All films remained on the substrate except for the $80 \mathrm{~nm}$ Ir film which exhibited a large residual stress. After three attempts, most of the Ir coating was ripped off the silicon 
substrate as illustrated in Figure 8. A buckling delamination effect is shown in Figure 1 which can result in a ripple effect on the coating. This is clearly indicated by the vertical lines in the coating on the 3rd attempt.

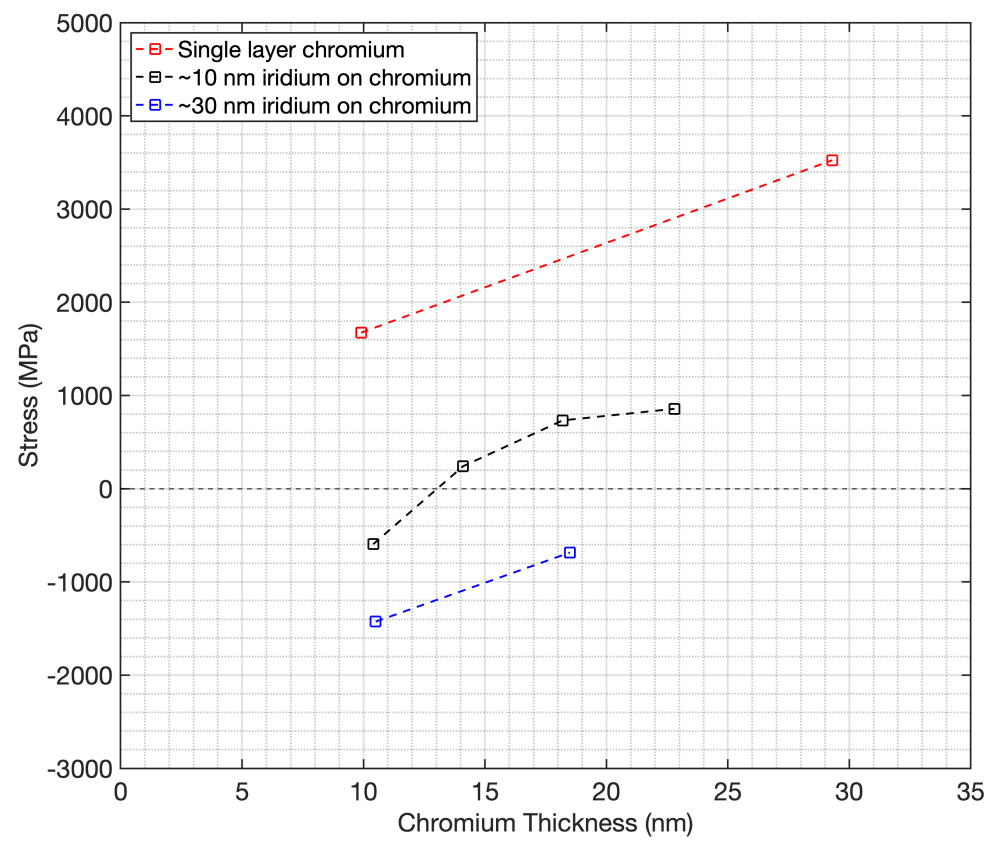

Figure 7: Residual stress of single layer Cr films and Cr/Ir bilayer films.
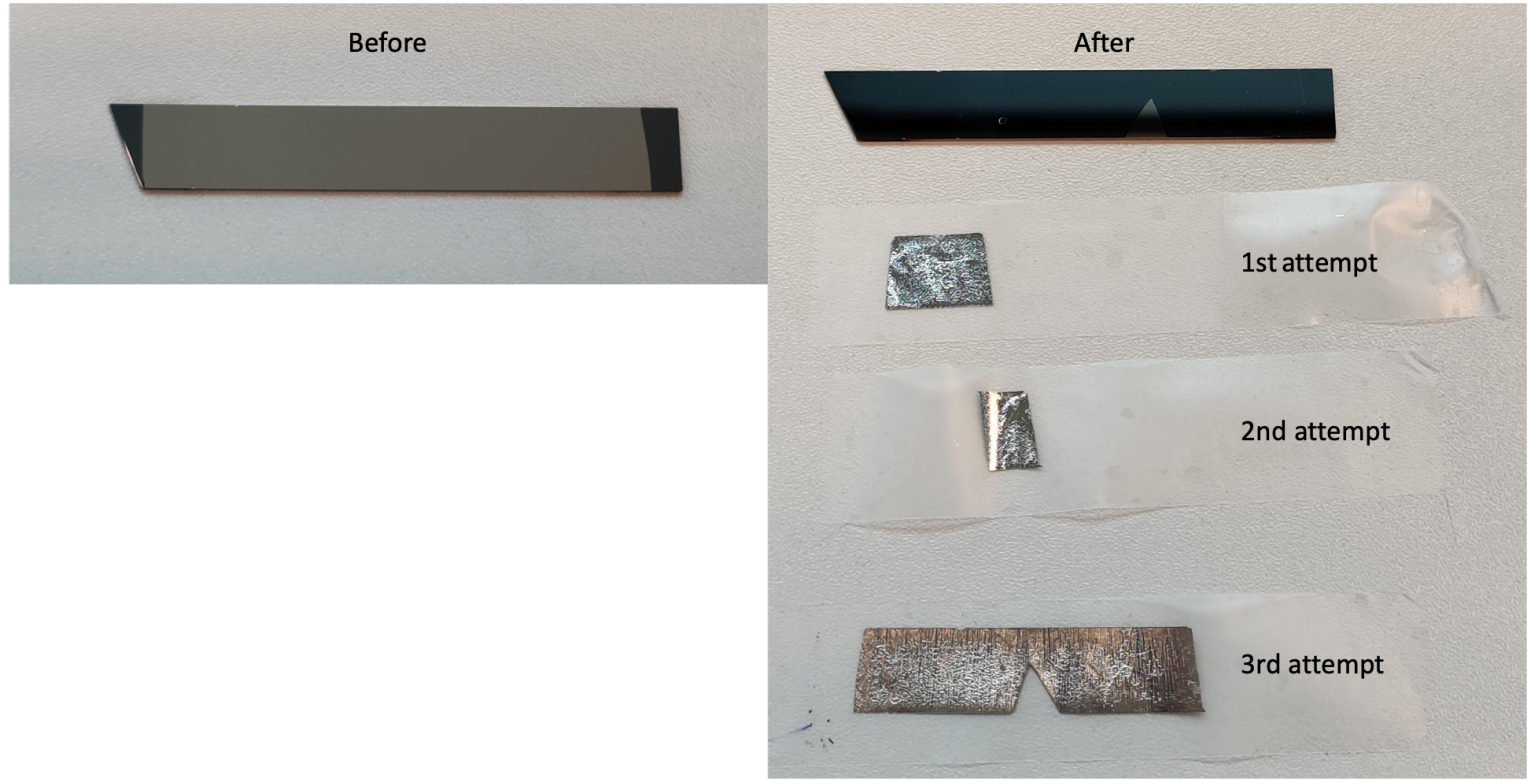

Figure 8: Tape test on single layer Ir film with a thickness of $80 \mathrm{~nm}$. The pattern observed on the 3rd attempt indicates the buckling delamination. 


\subsection{AFM}

The residual stress results indicate that a $\mathrm{Cr}$ thickness between 10.3 and $14.0 \mathrm{~nm}$ can counterbalance the compressive stress of a $9.9 \mathrm{~nm}$ thick Ir film. Assuming a linear interpolation, the zero stress is obtainable at a Cr thickness of $13 \mathrm{~nm}$. We performed AFM on samples cs00166 with $10.3 \mathrm{~nm} \mathrm{Cr}$ and cs00168 with $14.0 \mathrm{~nm}$ Cr. The AFM images were processed and analyzed using Gwyddion and the TOPO software package ${ }^{26}$. Before computing the RMS roughnesses, the data were subjected to background subtraction and line correction. The background was removed utilizing a tool in Gwyddion that combines facet and polynomial levelling. Due to the line-by-line data acquisition, the surface profile data can have scan lines with slightly different slopes or shifts. This scan line mismatch was corrected with a method that aligns the rows by fitting a third degree polynomial to each scan line and subtracting it from the line.

The processed AFM height data of cs00166 and cs00168 are shown in Figure 9. For each AFM image, we computed the RMS surface roughness using

$$
\sigma=\sqrt{\frac{1}{N} \sum_{n=1}^{N}\left(z_{n}-\bar{z}\right)^{2}} .
$$

where $N$ is the number of measurement points in a scan and $\bar{z}$ denotes the mean value of the height data.

The images derived from AFM show that both samples have high surface quality with RMS roughness ranging between $0.16 \mathrm{~nm}$ and $0.24 \mathrm{~nm}$. The difference we observe in the surface roughness derived from XRR and AFM measurements is explained by the wider range of frequencies covered by the XRR technique compared to the AFM technique.

We observed one contamination particle on sample cs00168 (scan 2) with a maximum height of $4.2 \mathrm{~nm}$ above the mean image plane.

With the processed AFM height data, we used the TOPO software to compute the average power-spectral-density (PSD) as a function of spatial frequency along the horizontal direction of the image array ( $\mathrm{x}$-direction). Figure 10, shows the average PSD calculated for the three scan areas of each of the two samples.

An estimation of the RMS roughness $\sigma$ was obtained as the square root of the integral of the one-dimensional PSD function in a given range of spatial frequencies,

$$
\sigma=\sqrt{2 \int_{f_{\min }}^{f_{\max }} \operatorname{PSD}(f) d f}
$$

In this case, we selected a spatial frequency range between $10^{-2}$ and $10^{-1} \mathrm{~nm}^{-1}$ as indicated by the grey-shaded areas. The RMS roughness values derived from the integrated PSD were consistently lower than those obtained from the RMS average of height deviations in the AFM data. The difference in the surface roughness derived from the PSD and the AFM height profile data is due to the fact that the roughness computed by eq. 1 only considers the vertical distribution of the roughness, whereas the roughness computed from eq. 2 is also sensitive to the lateral structures. 
Table 4: Surface RMS roughnesses of Cr/Ir bilayers computed from AFM surface profile data and from integration of the averaged 1D PSD function in the spatial frequency range $10^{-2}$ and $10^{-1} \mathrm{~nm}^{-1}$.

\begin{tabular}{|c|c|c|c|}
\hline \multicolumn{2}{|c|}{ Scan area } & RMS roughness (nm) & RMS roughness $(\mathrm{nm})$ \\
\hline \multirow{3}{*}{ cs00166 } & Scan 1 & 0.16 & 0.09 \\
\hline & Scan 2 & 0.15 & 0.11 \\
\hline & Scan 3 & 0.20 & 0.15 \\
\hline \multirow{3}{*}{$\operatorname{cs} 00168$} & Scan 1 & 0.24 & 0.17 \\
\hline & Scan 2 & 0.24 & 0.16 \\
\hline & Scan 3 & 0.19 & 0.12 \\
\hline
\end{tabular}
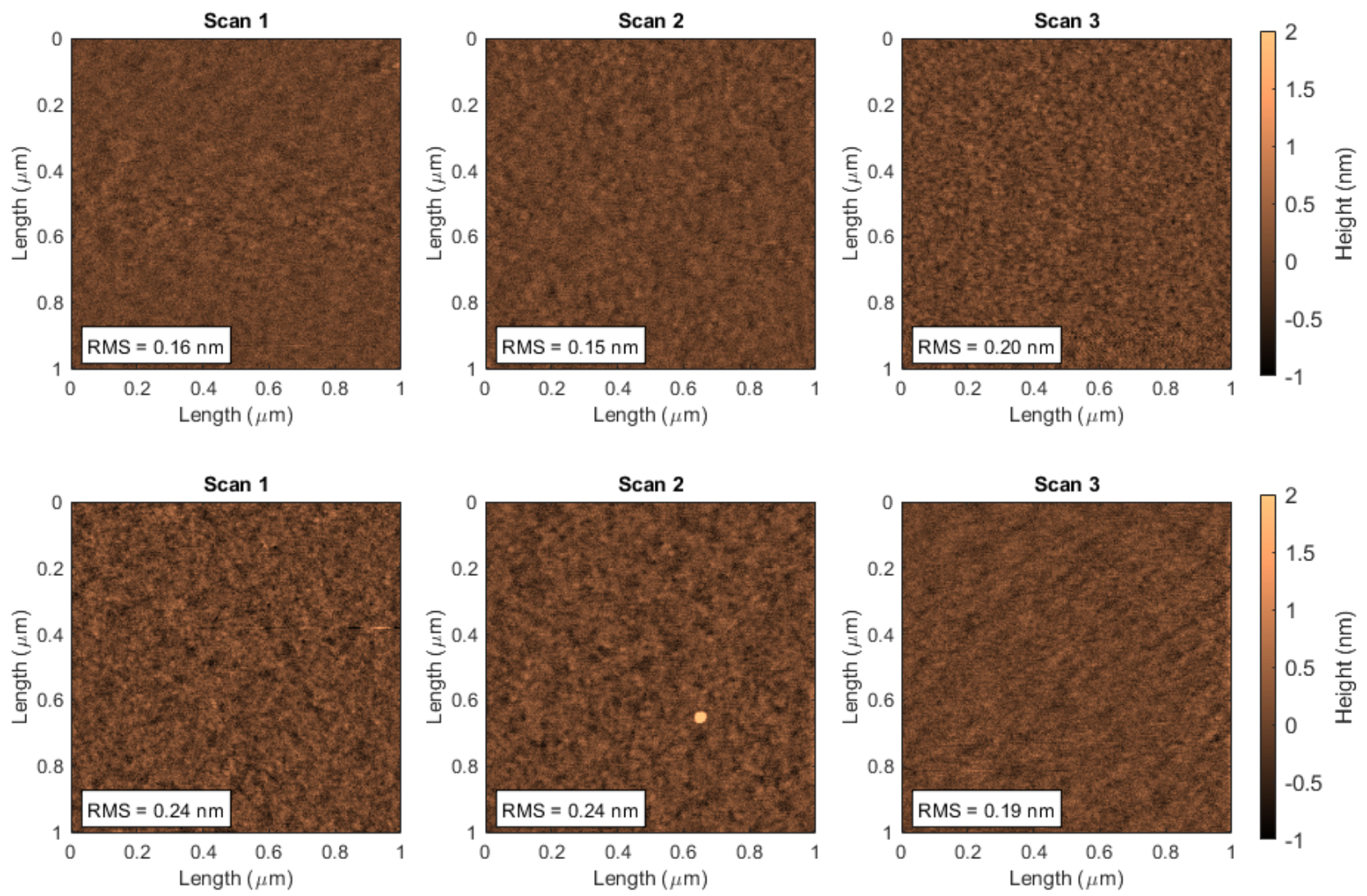

Figure 9: AFM images of three different positions on cs00166 (top row) and cs00168 (bottom row). 

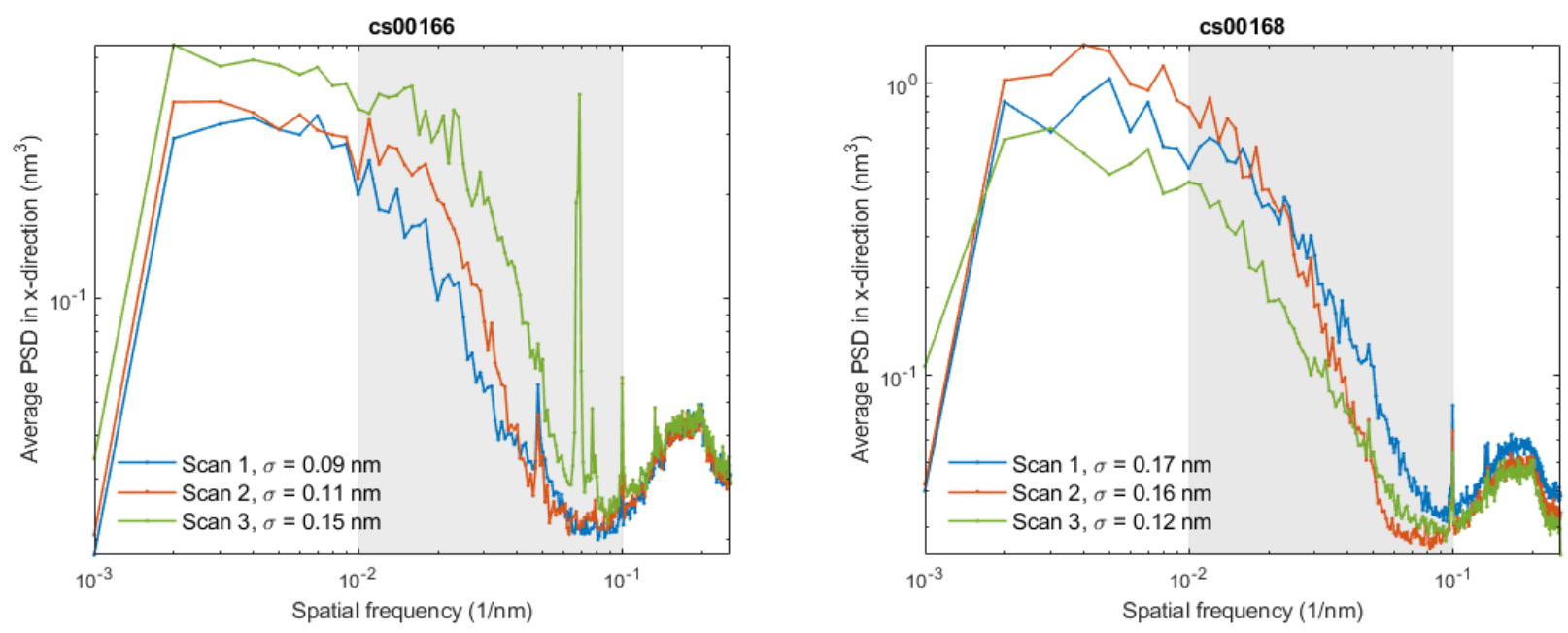

Figure 10: The average PSD in the scan direction as a function of the spatial frequency calculated from AFM images of three positions on samples cs00166 (left) and cs00168 (right). The RMS roughness $\sigma$ is calculated from the portion of the PSD contained within the spatial frequency range $10^{-2}$ and $10^{-1} \mathrm{~nm}^{-1}$ as indicated by the shaded area.

\section{SUMMARY}

We investigated the residual stresses of single layer $\mathrm{Cr}$ thin films and the combined residual stresses of $\mathrm{Cr}$ and $\mathrm{Ir}$ bilayer films deposited on smooth silicon substrates using DC magnetron sputtering. We derived the thin film properties, such as thickness, density and roughness utilizing XRR and AFM. We determined that Cr thin films with thicknesses ranging from 5-30 nm exhibit residual tensile stress and that Ir thin films with thicknesses 10 $\mathrm{nm}$ and $30 \mathrm{~nm}$ exhibit residual compressive stress. Cr films of varying thicknesses were deposited underneath 10 $\mathrm{nm}$ Ir films, and we identified that a Cr film thickness of $13 \mathrm{~nm}$ is suitable to balance the stress of the Ir film. We also identified that a single layer Ir film with a thickness of $80 \mathrm{~nm}$ exhibited an excessive stress level resulting in a buckling delamintation of the film. This was shown through a tape test study.

We investigated the impact of including $\mathrm{Cr}$ underneath the Ir thin films. The results indicated that the surface roughness of the Ir film increased slightly when deposited on top of $\mathrm{Cr}$ due to the high Cr roughness. Ir and $\mathrm{Cr}$ make a good pair as chromium counterbalance the residual stress of Ir and Ir grows with a low surface roughness on top of chromium.

\section{ACKNOWLEDGEMENT}

This activity has been funded by the European Space Agency under contract AO/1-8285/15/NL/BW .

\section{REFERENCES}

1. D. M. Broadway et al., "Achieving zero stress in iridium, chromium, and nickel thin films," Proceedings of Spie - the International Society for Optical Engineering 9510, p. 95100E, 2015.

2. K.-W. Chan, M. Sharpe, W. Zhang, L. Kolos, M. Hong, R. McClelland, B. Hohl, T. Saha, and J. Mazzarella, "Coating thin mirror segments for lightweight x-ray optics," in Optics for EUV, X-Ray, and Gamma-Ray Astronomy VI, S. L. O'Dell and G. Pareschi, eds., 8861, p. 88610X, 2013. 
3. M. Berdova, "Micromechanical characterization of ald thin films," 2015.

4. D. E. Graessle et al., "Iridium optical constants for the Chandra X-ray Observatory from reflectance measurements of 0.05-12 keV," in X-Ray and Gamma-Ray Instrumentation for Astronomy XIII, K. A. Flanagan and O. H. W. Siegmund, eds., 5165, pp. 469 - 481, International Society for Optics and Photonics, SPIE, 2004.

5. M. Bavdaz et al., "Optics developments for athena," Applications of Digital Image Processing 11119, p. 111190D, 2019.

6. M. J. Collon et al., "Status of the silicon pore optics technology," Proceedings of Spie 11119, p. 111190L, 2019.

7. D. D. M. Ferreira et al., "Development and characterization of coatings on Silicon Pore Optics substrates for the ATHENA mission," Proceedings of SPIE 8443, p. 84435E, 2012.

8. D. D. M. Ferreira et al., "Coating optimization for the ATHENA+ mission," Proceedings of SPIE 8861, p. $886112,2013$.

9. D. D. M. Ferreira et al., "X-ray mirror development and testing for the ATHENA mission," Proceedings of SPIE 9905, p. 99055K, 2016.

10. D. D. M. Ferreira et al., "Design, development, and performance of x-ray mirror coatings for the Athena mission," Proceedings of SPIE , 2017.

11. D. D. M. Ferreira et al., "Performance and stability of mirror coatings for the ATHENA mission," Proceedings of Spie 10699, p. 106993K, 2018.

12. S. Svendsen et al., "Performance and time stability of $\mathrm{Ir} / \mathrm{SiC} \mathrm{X}$-ray mirror coatings for ATHENA," in Proceedings of SPIE 11119, Optics for EUV, X-Ray, and Gamma-Ray Astronomy IX, 11119, 2019.

13. S. Svendsen et al., "Status of the Ir/SiC coating development for the Athena optics," SPIE - International Society for Optical Engineering, 2020.

14. S. Massahi et al., "Development and production of a multilayer-coated X-ray reflecting stack for the Athena mission," Proceedings of Space Telescopes and Instrumentation 2016: Ultraviolet To Gamma Ray 9905, p. 99055P, 2016.

15. S. Massahi et al., "Investigation of photolithography process on spos for the athena mission," Proceedings of Spie 9603, p. 96030M, 2015.

16. S. Massahi et al., "Investigation of boron carbide and iridium thinfilms, an enabling technology for future x-ray telescopes," Applied Optics, 2020.

17. P. L. Henriksen et al., "Lexr: A low-energy x-ray reflectometer for characterization of athena mirror coatings," Proceedings of Spie 11119, p. 111191F, 2019.

18. P. L. Henriksen et al., "Qualification and performance of the Low-Energy X-ray Reflectometer (LEXR)," Proceedings of Spie, 2020.

19. D. L. Windt, "IMD - Software for modeling the optical properties of multilayer films," COMPUTERS IN PHYSICS 12(4), pp. 360-370, 1998.

20. S. Massahi, Industrialization of the mirror plate coatings for the ATHENA mission. PhD thesis, Technical University of Denmark, 2019.

21. J. P. Sheehy et al., Handbook of Air Pollution, Environmental health series: Air pollution, U.S. Department of Health, Education, and Welfare, Public Health Service, Bureau of Disease Prevention and Environmental Control, National Center for Air Pollution Control, 1968. 
22. "Angstrom Sciences - Density of elements chart." https://www.angstromsciences.com/ density-elements-chart/. [Online; accessed 26-November-2020].

23. M. R. Ardigo, M. Ahmed, and A. Besnard, "Stoney formula: Investigation of curvature measurements by optical profilometer," Advanced Materials Research 996, pp. 361-366, 2014.

24. G. Peng, F. Wu, and J. Lin, "Residual stress of chromium, magnetic, and carbon films," Ieee Transactions on Magnetics 35(5), pp. 3004-3006, 1999.

25. S. Y. Grachev et al., "Stress in sputter-deposited cr films: Influence of ar pressure," Journal of Applied Physics 97(7), p. 073508, 2005.

26. D. L. Windt, "Multilayer films for figured x-ray optics," Proceedings of Spie 3448, pp. 280-290, 1998. 